\title{
Kuech, Renschler, and Tsai to Chair 1996 MRS Spring Meeting
}

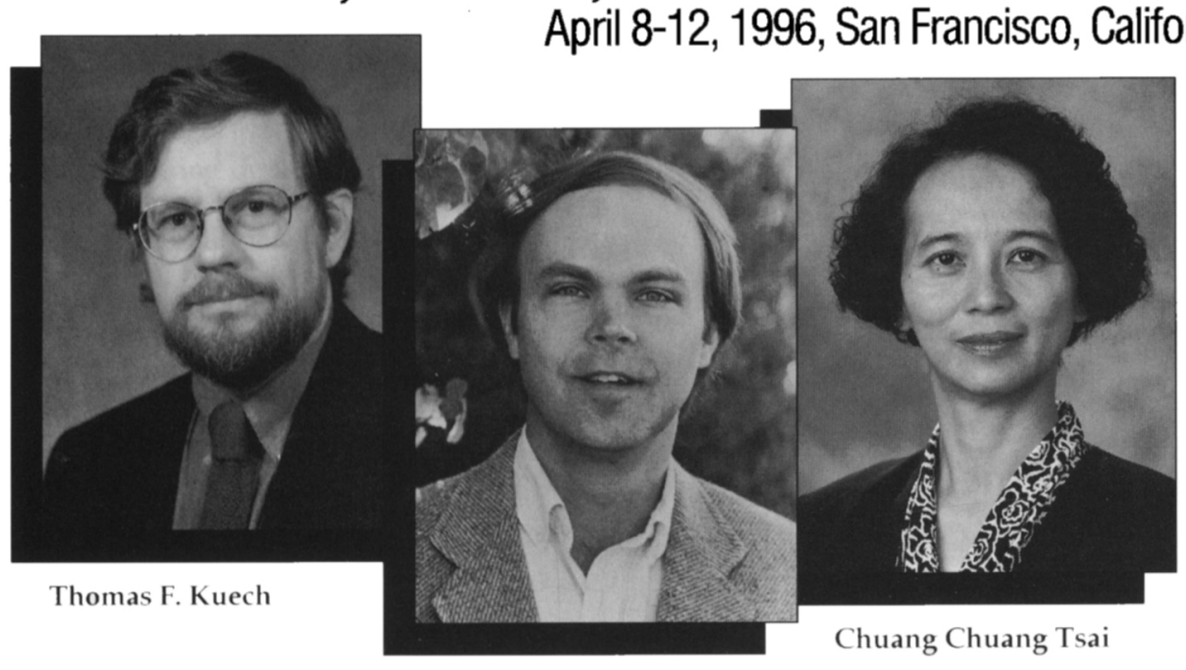

Clifford L. Renschler

Thomas F. Kuech, Clifford L. Renschler, and Chuang Chuang Tsai will chair the 1996 MRS Spring Meeting in San Francisco.

The meeting will feature 28 symposia covering a broad range of materials science and engineering as well as processing topics. This meeting provides a set of strong topical symposia that cross conventional research boundaries, continuing the MRS practice of providing a forum for the exchange of information across disciplines that are at the leading edge of materials research.

A set of traditional MRS symposia offered includes elemental and compound semiconductors, nitrides and other wide bandgap semiconductors, amorphous silicon and display materials, ceramics, superconductors, rapid thermal processing, and photovoltaics.

Several symposia will focus on emerging areas of materials research including microporous and mesoporous materials, novel polymer architectures, innovation in instrumentation, geochemistry of oxides, and hybrid organic and inorganic materials.

Tutorial reviews on topics featured in selected symposia will be offered in addition to Symposium X, Frontiers in Materials Research. An exhibit will accompany the technical symposia.

Thomas F. Kuech is a professor of chemical engineering at the University of Wisconsin-Madison. He received his PhD degree from the California Institute of Technology in applied physics, and an MS degree in materials science and BS degree in physics from Marquette University. Prior to his present position he was manager of an epitaxial growth effort at the IBM T.J. Watson Research Laboratory, responsible for the development of materials and structures for both electronic and photonic devices. His research interests include metal organic vapor phase epitaxy (MOVPE) of compound semiconductors, materials characterization, and device fabrication as well as physics of semiconductors and electronic device structures.

$\mathrm{He}$ is the coauthor of over 160 publications and the holder of several patents.

$\mathrm{He}$ has received several awards, including an IBM Outstanding Innovation Achievement Award for discovery of long-range order in alloy semiconductors (1986) and for identification of doping mechanisms in MOVPE (1989), and the 1987 Young Authors Award from the American Association for Crystal Growth. Kuech served as principal author in several MRS symposia. He is active in materials science-related organizations such as the American Association for Crystal Growth and the American Vacuum Society, both serving as an officer and organizing conferences in the areas of crystal growth and epitaxy.

Clifford L. Renschler is manager of the Properties of Organic Materials Department at Sandia National Laboratories. His department is responsible for development and characterization of novel organic and organic/inorganic hybrid materials for weapons, energy, and industrial applications. Renschler received his BS degree in chemistry from the University of Evansville in 1977, and received his PhD degree in analytical chemistry at the University of Illinois in 1981. He then joined Sandia in Albuquerque as a member of the technical staff. He also serves as manager of the Materials and Process Sciences Technical Communications Department.
Renschler's research interests include energy transfer among small molecules in polymer hosts, plastic scintillator design, radioluminescent lights, photodegradation kinetics of polymers and stabilizers, and the fabrication of carbon films and devices from the pyrolytic decomposition of polymeric precursors. He has authored over 35 technical publications and a book chapter, and holds four patents.

He co-organized symposia on "Novel Forms of Carbon" at the 1992 and 1994 MRS Spring Meetings. He also participates in the Sandia School Partnership Program in which Sandia employees demonstrate science principles at local schools. He is a member of the American Chemical Society.

Chuang Chuang Tsai is a research staff member at the Electronics and Imaging Laboratory at Xerox Palo Alto Research Center. She received her BS degree in physics from the National Taiwan University in 1972, and her MS and PhD degrees in physics from the University of Chicago in 1973 and 1978, respectively.

Tsai's research interests focus on the relationship among material properties, processing, and device performance of thin films used in the large-area electronics applications, such as active matrix liquid crystal displays, and page-wide image scanners. Her work includes research on amorphous- and polycrystalline-silicon thin-film transistors (TFTs); microcrystalline silicon; silicon nitrides, carbides, and oxides; low-temperature silicon epitaxy; superlattices; plasma-enhanced chemical vapor deposition; film-growth mechanisms; defect passivation by hydrogen in TFTs; hydrogen diffusion in silicon; metal/silicon interfaces; Schottky barrier formation; amorphous-silicon-based NIP and Schottky photodiodes; and lightinduced degradation effects and metastable defect creation. She is the coauthor of nearly 100 publications, including patents, in these areas, and edited two books on the materials science of microand nanocrystalline semiconductors.

Tsai has co-organized three MRS symposia on the materials science and device applications of microcrystalline and nanocrystalline semiconductors. For more than 10 years she has been a contributor to the technical program of the MRS meetings. In addition, she is a senior member of IEEE and a member of the American Physical Society, the Society for Imaging Science and Technology, and the Society for Information Display. 